\title{
Develando prejuicios: ¿Por qué los hombres homosexuales son padres de segunda categoría?
}

Homossexualidade e adoção.

UZIEL, Anna Paula.

Rio de Janeiro: Garamond, 2007. 224 p.

Tener hijos, en nuestra cultura, es considerado como algo esencial para la realización personal y para la sobrevivencia de la sociedad. Se espera que las parejas, tarde o temprano, se conviertan en padres. Sin embargo, al desear hijos, las personas y parejas homosexuales no se acercan, sino que se alejan de las expectativas sociales. Homosexualidad y parentalidad son vistos como antagónicos e incompatibles por la sociedad. A pesar de ello, no es un hecho nuevo el que gays y lesbianas sean madres y padres, ya sea a raíz de relaciones heterosexuales y, más recientemente, mediante la adopción y las nuevas tecnologías reproductivas.

En su libro Homosexualidad y adopción Anna Paula Uziel, doctora en antropología social y psicóloga social del Instituto de Psicologia da Universidade do Estado do Rio de Janeiro (UERJ), da cuenta de las ideas preconcebidas, los mitos y los miedos que surgen cuando se habla de adopción por parte de homosexuales en el Brasil de hoy. Su análisis le permite interpelar los discursos clásicos sobre la familia para volver a preguntar ¿Qué significa ser padre? ¿Sobre qué base se puede decidir quién será un buen padre? ¿Qué y quiénes constituyen una familia?

Uziel combina dos temas que por sí solos plantean importantes desafíos a las formas 
tradicionales de hacer familia. Por un lado la adopción, que permite una filiación sin vínculo biológico, es decir, desafía el núcleo de nuestras ideas de lo que es el parentesco.' Aquí el parentesco se construye mediante el lazo legal y se mantiene a través de los cuidados cotidianos. Históricamente la adopción ha pretendido mantener la ficción de la familia nuclear tradicional creando una representación de una pareja coherente con el modelo biológico básico. ${ }^{2}$ Por otro lado, la homosexualidad, que hace imposible mantener esta ficción, ya que cuestiona la centralidad del sexo procreativo y la diferencia de sexo como base de la familia.

El libro se divide en dos partes. En la primera, la autora presenta una discusión de los desafíos que plantean los nuevos arreglos familiares. Para esto revisa los elementos que pueden ser un aporte al análisis de los temas centrales del libro Homosexualidad y adopción - presentes en las familias monoparentales, las familias pluriparentales y las familias recompuestas. Aquí Uziel concluye que sexualidad y parentalidad son esferas distintas de la vida y que las funciones parentales no implican el ejercicio de la sexualidad.

En la segunda parte del libro, Uziel se centra en los elementos que entran en juego en la adopción por parte de personas homosexuales. Para ello se basa en entrevistas realizadas a técnicos y operadores que trabajan en los procesos de adopción y en los documentos de 8 procesos de adopción donde el solicitante es homosexual. Notablemente 6 de estos procesos fueron favorables en su resultado final para los solicitantes. Esto da cuenta de un avance hacia el reconocimiento del derecho de las personas homosexuales a tener hijos.

Uziel realiza un análisis rico y profundo de los discursos y posiciones de psicólogos, asistentes sociales, promotores, defensores públicos y jueces. Creo que es un acierto dar cuenta de las narrativas de estos actores ya que en su actuar cotidiano y en las interpretaciones que hacen de la legislación, ellos están tomando decisiones respecto a quiénes pueden y quiénes no pueden convertirse en padres y por lo tanto, están definiendo qué significa ser un buen padre hoy en Brasil.

La autora analiza no sólo lo explícito en las palabras de sus entrevistados, sino que lee entrelíneas e interpreta también los silencios. De esta forma logra ir más allá del discurso políicamente correcto que le presentan los técnicos y operadores. En un primer nivel éstos son abiertos y tolerantes, pero al observar con más cuidado Uziel devela cómo en las narrativas de estos profesionales surgen los clásicos prejuicios, miedos y mitos asociados con la homosexualidad. Un ejemplo de ello es la recurrente asociación de homosexualidad con promiscuidad.

Resulta provocador el foco del libro en la homoparentalidad masculina. Ya por sí sola la paternidad de un hombre, sin una mujer a su lado, resulta controversial. La crianza de los hijos está tradicionalmente asociada a lo femenino. Es curioso como los técnicos resaltan características femeninas y maternales de los adoptantes homosexuales para argumentar su idoneidad como padres. De alguna manera, a sus ojos, la orientación sexual de estos candidatos a padres los acerca a la figura maternal y, por lo tanto, los hace más capaces de asumir la paternidad. Sería interesante poder comparar qué pasa con las solicitudes de mujeres lesbianas para adoptar. ¿Está el tema de su sexualidad igualmente presente en los procesos de adopción? ¿Son menos cuestionadas al ser mujeres?

Es revelador que técnicos y operadores tiendan a cuestionar más la homoparentalidad en pareja que la paternidad individual de hombres homosexuales. El sentido común indica que es menos difícil criar un hijo entre dos y que para el niño es mejor tener dos personas que lo quieran, lo guíen y lo protejan. Sin embargo, la sexualidad, que puede ser invisibilizada en el caso de adoptantes individuales, pasa a ocupar un lugar central cuando se trata de una pareja de personas del mismo sexo. Se desprende de los discursos de los entrevistados y del análisis de los procesos que la sexualidad homosexual sigue siendo considerada algo sucio, desviado y con un alto potencial de contaminar a las personas que están cerca de ella, especialmente a los niños.

A lo largo de las páginas del libro de Uziel hay una pregunta que persiste ¿Cuál es la pertinencia de hablar de sexualidad cuando se trata de parentalidad? De acuerdo con los resultados de su investigación el tema de la sexualidad surge sólo cuando el que solicita la adopción es homosexual. La autora se pregunta ¿influye la orientación sexual en la capacidad de criar niños? O iexiste una manera de ser padre diferente si se es homosexual o heterosexual? ¿Está relacionado el ejercicio de la parentalidad con la sexualidad? ¿Tiene sentido hablar de homoparentalidad? Creo que la autora toca aquí un tema clave para los estudios de familia y homosexualidad.

Un argumento para esgrimir que la homosexualidad y la parentalidad están relacionadas es que es en la familia y son los padres los que transmiten modelos de género y también sexuales a sus hijos. Los principales referentes de géne- 
ro y de relaciones de pareja que los niños tienen son entregados por sus padres. Sin embargo, aún sosteniendo la pertinencia de hablar de homoparentalidad cabe preguntarse ipor qué el modelo de pareja homosexual es un mal modelo para los niños? Lo que está detrás es la idea de que la homosexualidad es algo desviado, negativo y que debe ser evitado. Al parecer, pesar de los avances respecto a la tolerancia a la diversidad sexual en Brasil, no se ha logrado construir una imagen positiva del ser homosexual. Esto está claramente reflejado en el análisis de los procesos y las entrevistas realizadas por Uziel. Los padres homosexuales pueden cumplir todas las funciones tradicionalmente atribuidas a la parentalidad (socialización, cuidados, entrega de una identidad, protección, afectividad, etc.) $Y$, como señala Uziel, en muchos sentidos una pareja homosexual que cría un hijo no se distancia demasiado de la familia nuclear tradicional. En ambos casos la pareja conyugal es la misma que la pareja parental (entendida esta última como los padres que crían al niño). ${ }^{3}$

Uziel aborda lúcidamente un tema trascendental tanto para los estudios de familia como para nuestras sociedades. El reconocimiento legal y judicial de los vínculos entre padres homosexuales y sus hijos es vital para alcanzar el reconocimiento social. Hequembourg y Farrell ${ }^{4}$ señalan que a los padres y madres de mujeres lesbianas que no han adoptado legalmente a sus hijos no biológicos les es más difícil sentirse abuelos ya que sienten que el vínculo con sus nietos es más precario. No se debe olvidar que las familias constituidas por personas homosexuales se inscriben en contextos más amplios de familia extensa (abuelos, tíos y primos), instituciones escolares, instituciones de salud, etc. La plena aceptación por parte de estos contextos es vital para el desarrollo sano y feliz de los niños adoptados por personas homosexuales.
Creo que Uziel acierta al comparar la homoparentalidad con el divorcio, un cambio ahora asimilado pero que en su momento causó mucho revuelo y sin duda es una transformación importante en las formas que puede tomar la familia. El libro Homosexualidad y adopción es un gran aporte que nos ayuda a comprender las resistencias que encuentran las nuevas formas de construir familia.

\section{Notas}

' David SCHNEIDER, 1980.

${ }^{2}$ Anne CADORET, 2003.

${ }^{3}$ CADORET, 2003; y Florencia HERRERA, 2009.

${ }^{4}$ Amy HEQUEMBOURG y Michael FARREL, 1999.

\section{Referencias bibliográficas}

CADORET, Anne. Padres como los demás: homosexualidad y parentesco. Barcelona: Gedisa, 2003.

HEQUEMBOURG, Amy; FARRELL, Michael. "Lesbian Motherhood: Negotiating Marginal-mainstream Identities." Gender and Society, v. 13, n. 4, p. 540-557, 1999.

HERRERA, Florencia. "Tradition and Transgression: Lesbian Motherhood in Chile." Sexuality Research \& Social Policy: Journal of NSRC, University of California Press, v. 6, n. 2, p. 35-51, 2009. ISSN 1553-6610.

SCHNEIDER, David. American Kinship: A Cultural Account Second Edition. London: The University of Chicago Press, 1980.

WEEKS, Jeffrey; HEAPHY, Brian; CATHERINE, Donovan. Same Sex Intimacies: Families of Choice and Other Life Experiments. London: Routledge, 2001.

WESTON, Kath. Families We Choose: Lesbians, Gays, Kinship. New York: Columbia University Press, 1991.

Florencia Herrera Universidad Diego Portales, Chile 